
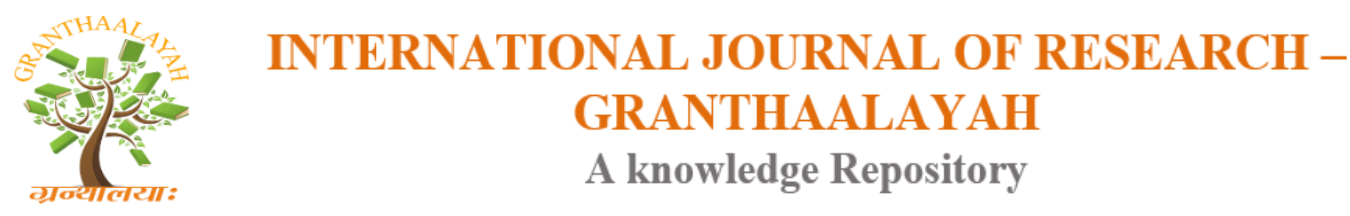

Science

\title{
LONG TERM IMPLICATIONS OF CLIMATE CHANGE ON RURAL DEVELOPMENT IN NIGERIA
}

\author{
Ewubare Dennis Brown *1, Ajisafe Femi Sammy ${ }^{1}$ \\ ${ }^{* 1}$ Department of Agricultural and Applied Economics, Rivers State University
}

\begin{abstract}
This paper examined the effects of climate change on rural development in Nigeria. In this paper, rural development was measured by the percentage of the population with access to improved water supply. On the other hand, the measures of climate change employed in this paper are precipitations, variations in temperature and per capita carbon dioxide emissions. Data on the variables were sourced from the World Development Indicators (WDI) and the analytical techniques include descriptive statistics, unit root test, Hansen cointegration test and FullyModified Least Squares (FMOLS). The Kwiatkowski Phillips Schmidt and Shin (KPSS) unit test results show that the variables are mixed integrated with combinations of I(0) and I(1). It was observed from the Hansen test for cointegration that the test statistic with probability value (0.192) indicates that the variables are cointegrated. This suggests that the null hypothesis of parameter stability cannot be rejected. It was found from the estimated cointegrating regression model that precipitation and temperature are significant in influencing changes in access to improved water supply in rural Nigeria. Whilst precipitations negatively influenced access to rural water supply, changes in temperature enhanced rural water supply. The negative effects of precipitations on rural water supply could be attributed to the flooding usually associated with precipitations which tend to contaminate the various water sources in the rural areas. On the other hand, per capita carbon dioxide emissions do not significantly affect access to improved water supply in rural area. Given the findings, it was recommended for policy makers to adopt proactive and innovative approaches by synergizing with the relevant stakeholders to significantly address the problem of climate change and improve opportunities for rural development.
\end{abstract}

Keywords: Rural Development; Climate Change; Water Supply and Weather variations.

Cite This Article: Ewubare Dennis Brown, and Ajisafe Femi Sammy. (2018). "LONG TERM IMPLICATIONS OF CLIMATE CHANGE ON RURAL DEVELOPMENT IN NIGERIA." International Journal of Research - Granthaalayah, 6(9), 340-350. https://doi.org/10.5281/zenodo.1451855.

\section{Introduction}

The frequency of climate change in recent time has continued to threaten sustainable development. Several studies (Ayers and Huq, 2009; Boyd et al. 2009) have shown that climate change poses a 
huge threat to development in poor countries, where the incidences of poverty and inequality are very high. Although the understanding of the overall implications of climate change is still underway, empirical studies suggest that precautionary and prompt action is important (Schneider et al, 2000). It is also argued that climate change can no longer be overlooked in the development debate. This is partly as a result of it growing adverse implications on developing economies and regions including sub-Saharan Africa. The vulnerability of African economies to climate change is also acknowledged by Bunce, Rosendo and Brown (2010), who argued that African continent stands the risk of global food crisis unless the evolving issues of climate change is adequately addressed.

The adverse effects of climate change on sub-Saharan African have continued to undermine the successes achieved in the key indicators of socio-economic development both in urban and rural areas. More so, the changing dimensions of precipitation and temperature patterns are increasingly being attributed to global climate change patterns. Holmgren and Oberg (2006) observed that rainfall patterns in sub-Saharan African are increasingly becoming less predictable and precipitation has declined on the average while temperature continues to increase. Additionally, Mano and Nhemachena (2007) and Biggs et. al., (2008) observed that the increasing temperatures and decline in precipitation levels have the potentials of contracting agricultural production in subSaharan Africa. In other words, rural development is often endangered by the incidences of climate change. Dube and Phiri (2013) observed that the vulnerability of rural communities in Africa to variations in climate change seems to intensify the poverty problem and worsen the problem of environmental degradation.

Most of the people affected by the incidences climate change in sub-Saharan Africa are resident in rural communities and urban unplanned settlements (World Health Organization, WHO, 2012). However, some of the areas that seem to be adequately served with improved sources of water, the quality is not assured and hence the proportion of the population with access to improved sources does not translate into access to safe water supply. As such, large numbers of the population are without access to safe drinking water in Africa, especially in the sub-Saharan region. In Nigeria, the varying climatic conditions+ have continued to threaten rural development due to their negative effects on improved water supply. The supply of water in rural areas has remained a common course of concern to policy makers and development partners. The water sources in rural Nigeria include streams, rivers, and in certain areas springs. These sources have been identified by Djakou (2013) as very vulnerable to climate change.

On the whole, rural water supply in Nigeria has suffered numerous setbacks and it is more threatened by the increasing challenges of climate change. The WHO (2009) report indicates that rural water coverage in Nigeria stood at 45 percent compared to 40 percent in 1990, thus, depriving 237 million access to portable water supply. Compared to the rural areas, urban water coverage in Nigeria is quite high as it stood at 83 per cent in 2000 leaving 37 million urban residents without access. This is a pointer that in Nigeria the rural communities lag behind the urban areas in terms of water supply. In spite of the continued government investment in water supply in rural communities, the incidences of climate change have continued to pose challenges to the development of rural communities. These provoked questions as: How has rising temperatures influenced rural water supply? What effect does the changing rainfall have on rural water supply? Is rural water supply adversely influenced by greenhouse emissions? Accordingly, efforts were 
made in this study to provide answers to these questions in order to deepen the understanding of the implications of climate change on rural development.

\subsection{Objectives of the Study}

This main objective of this paper is to determine the effect of climate change on rural development in Nigeria. In view of this broad objective, this paper specifically seeks to:

1) determine the effect of precipitation on rural water supply in Nigeria.

2) examine how average temperature influences rural water supply in Nigeria.

3) analyse the effect of per capita carbon dioxide emissions on rural water supply in Nigeria.

\section{Review of Related Literature}

\subsection{Theoretical Literature}

\subsubsection{Anthropogenic Global Warming (AGW) Theory}

This theory assumes that climate change scenarios such as carbon dioxide $\left(\mathrm{CO}_{2}\right)$, methane, and nitrous oxide induce detrimental effects on the temperature. In the AGW theory, greenhouse gases are adjudged as major precursors of climate change with attendant implications on surface water. The AGW theory assumes that the positive feedbacks associated with greenhouse emissions increase the effects of these gases between two and four-fold. A small increase in temperature is believed to cause more evaporation, which places more water vapor in the atmosphere, thereby causing more warming. Proponents of the AGW theory believe that human induced carbon dioxide emissions are responsible for floods, droughts, severe weather and ocean coral bleaching amongst others.

The increasing incidences of flood pose a great challenge to rural population, especially access of the rural population to portable water. This undermines sustained development of rural communities. The degradation of the environment following changing climatic conditions is identified in the AGW theory as a threat to development in view of its adverse implications on water source and means of livelihood. It is however, argued that the extent of degradation in the environment tends to aggravate and become more severe as temperatures continue to rise. Further argument offered by the proponents of the AGW theory is that reduction in greenhouse emissions is necessary in reducing the danger posed by climate change to the environment and rural development.

\subsection{Conceptual Framework}

The concept of rural development has received much attention in development economics literature - both in developed and the developing countries worldwide. It encompasses overall development of rural areas with a view to improving the quality of life of rural population. As multidimensional concept, rural development cuts across the development of agriculture and agroallied rural related activities, development of cottage industries and crafts, socio- economic infrastructure, and above all, the human capital in rural areas. Since rural development intends to reduce poverty, it must clearly be designed to increase production and raise productivity. It is 
believed that improved food supplies and nutrition, together with basic services such as health, education and cultural activities would directly improve the physical well-being and quality of life of the rural poor.

In essence, rural development may imply a broad based re-organization and mobilization of rural masses in order to enhance their capacity to cope effectively with the daily task of their lives and with changes consequent upon this. It is equally recognized in literature that improved food supplies and nutrition, together with basic services, such as health and education, not only directly improve the physical well-being and quality of life of the rural poor, but can also indirectly enhance their productivity and their ability to contribute to national economy. Given that the livelihoods of the majority of the world's rural population depend, either directly or indirectly, on the agricultural sector, agriculture is an obvious sector in which to concentrate efforts to promote growth. Indeed, the promotion of agricultural development and smallholder farmers with access to improved water supply, in particular, has always been a central feature of rural development policy.

Whilst agricultural development remains an integral part of rural development, it is not enough on its own to ensure overall development in rural areas. Other sectors or dimensions come into play in the process of rural development. These include amongst others quality healthcare, education and economic activities in both economic and social sectors including infrastructure development, where rural water supply, roads, transport and energy development are prioritized.

\subsection{Empirical Literature}

Dube and Phiri (2013) investigated the impact of climate change on the livelihood of rural communities with a focus on Matobo District in Zimbabwe. The study primarily seeks to understand how communities have been affected by climate change and how they are adapting to it as well as their perceptions about the gravity of the climate change phenomenon. The findings reveal that climate change generated harmful effects on livelihood in the study area. The adverse effects of climate change on physical geography triggered the loss of flora and fauna and other natural habitat that constituted the livelihoods of the local people. The study also shows that declining precipitation and rising temperatures due incidences of climate change are making farming increasingly more difficult, and thus worsening the problem of food insecurity in the area. The study however, suggested for step by step approach to addressing the consequences of climate change.

Huq et al. (2015) analysed the consequences of climate change on livelihood of smallholder agricultural communities of coastal Bangladesh. The study focused mainly on six physically and socio-economically vulnerable communities of south-western coastal regions. Primary data was elicited from focus group discussions and historical transect analysis was applied. In the course of the analysis three orders of impacts of climate change on smallholder farmers was observed and described. The first order impacts focused on increasing erosion of the capacity of local communities to mitigate vulnerability to climate change impacts. This situation led to the second order impacts, which significantly transformed the agricultural landscape and production patterns. The cumulative effects of the first and second order impacts sparked the third order impacts in the form of worsening community livelihood assets and conditions. 
Dube et al. (2016) examined the impacts of climate change on agro-based livelihoods across the African continent with emphasis on Eastern, Western, Southern Africa and the Sahel region. Content analysis was relied upon in the exploring past studies to gain better understanding of the implications of climate change. The study revealed that the impact of climate change is invariably negative across the whole of Africa as it contributes to loss of agricultural yields and a reduction of biodiversity. In view of the findings, the study recommended that the support for livelihood diversification should be intensified in accordance with the rural development planning.

Nhemachen et al (2010) measured the economic impacts of climate change on crop and livestock farming in Africa using a cross-sectional survey of over 8000 farming households from 11 countries in the sub-regions of East, West, North and Southern Africa. The study mainly analysed the response of net revenue from crop and livestock agriculture across various farm types and systems in Africa to changes in climatic conditions while controlling for the effects of key socioeconomic, technological, soil and hydrological factors on agricultural production. The results show evidence of negative implications of warmer and drier climates on farm revenues in general. It was further gathered from the result that small-scale mixed crop and livestock system predominantly typical in Africa is the most tolerant whereas specialized crop production is the most vulnerable to warming and lower rainfall. The study however, recommended for more proactive measures in reducing the incidences of climate change.

Ofoegbu (2017) explored the impacts of climate change on rural communities in Africa, including people's livelihoods, their adaptive capacity, coping practice and ability to engage in sustainable forest use and management of climate change adaptation. A desktop review approach was applied using the forest based rural communities of South Africa as a case study. The findings indicate that climate variability adversely influenced the rural people and their livelihoods. It was specifically found that Forest-based livelihoods are the most vulnerable to climatic change outcomes. Nevertheless, it was found that the people have developed coping mechanisms to cushion the effects of climate variability and change. The study also shows that the effectiveness and efficiency of the climate change mitigation strategies are largely limited by factors that are related mostly to their socioeconomic attributes.

\section{Methodology}

\subsection{Research Design}

The ex post facto research design was adopted for this study. The focus on this research design was provoked by the use of nature of data used for the empirical analysis.

\subsection{Model Specification}

A single equation set-up with rural water supply (proxy for rural development) as dependent variable while precipitations, average temperature and per capita carbon are introduce into the model as explanatory variables. The model is expressed is expressed in a functional as:

RUWA $=f(\mathrm{PRE}, \mathrm{TEM}, \mathrm{PCO})$ 
Where: RUWA, PRE, TEM, and PCO are rural water supply, precipitations, temperature and per capita carbon dioxide emissions.

The linear econometric expression of equation (3.1) is of the form:

$$
R U W A_{t}=\coprod_{0}+\bigcup_{1} P R E_{t}+\bigcup_{2} T_{E M}+\bigcup_{3} P C_{t}+U_{t}
$$

Where: $\bigcup_{0}$ denotes the intercept, $\bigcup_{1}-\bigcup_{3}=$ estimates of the explanatory variables, $U_{t}=$ random error process and $t$ depicts the period covered.

\subsection{Nature and Sources of Data Collection}

The data used in this study were obtained from documentary sources. The data were mainly collected from the World Bank WDI over the period 1990-2016.

\subsection{Method of Data Analysis}

The analytical technique for this study followed the Fully Modified Least Squares (FM-OLS) procedure credited to Phillips and Hansen (1990). It formed the basis for the estimation of the cointegrating regression model. The motivation for this technique lies on its ability to produce robust estimates for both small and relatively large samples. It is also preferred to the Ordinary Least Squares because of its non-parametric characteristics which makes it asymptotically equivalent to the maximum likelihood technique, thus, producing median-unbiased estimstes and overcomes the common restrictions of serial correlation. In addition to the FMOLS, descriptive statistics was utilized in analyzing the distribution of the variables. The diagnostics tests carried out in the cause of this study include unit root and cointegration tests as well as normality test and Wald test for coefficient restrictions.

Unit root test: The Kwiatkowski, Phillips, Schmidt and Shin (KPSS, 1992) approach to unit root was applied to determine if the series depict a unit root process. The null hypothesis of stationarity was tested against the alternative hypothesis of non-stationarity at 5 percent level. The equation for the unit root is expressed in its general form as:

$\Delta \mathrm{Y}_{\mathrm{t}}=B_{0}+B_{1} \mathrm{Y}_{\mathrm{t}-1}+\sum_{i=1}^{M} c_{i} \Delta Y_{\mathrm{t}-\mathrm{i}}+\mu_{\mathrm{t}}$

Where: $\mathrm{Y}_{\mathrm{t}}=$ time series under consideration, $B_{1}$ and $\mathrm{c}_{\mathrm{i}}=$ parameter estimates, $\mathrm{m}=$ lag length, $\Delta=$ First difference operator and $\mu_{\mathrm{t}}=$ stochastic error process.

Cointegration Test: The Hansen (1992) cointegartion test for coefficients stability was applied in this study. The null hypothesis of cointegration was tested against the alternative hypothesis of no cointegration. The rejection of the null hypothesis depicts instability in the parameters. The test statistic applied in the Hansen cointegration test emanates from the theory of Lagrange Multiplier for parameter instability. 


\section{Findings and Discussion}

\subsection{Descriptive Statistics}

The descriptive statistics for the series are summarized in Table 4.1

Table 4.1: Summary of descriptive statistics

\begin{tabular}{|l|l|l|l|l|}
\hline & RUWA & PRE & TEM & PCO \\
\hline Mean & 41.48889 & 94.27815 & 27.21741 & 0.541852 \\
\hline Median & 41.60000 & 94.73000 & 27.36000 & 0.570000 \\
\hline Maximum & 57.30000 & 111.7800 & 27.83000 & 0.770000 \\
\hline Minimum & 24.60000 & 76.60000 & 26.01000 & 0.330000 \\
\hline Std. Dev. & 10.23735 & 8.615539 & 0.406766 & 0.145286 \\
\hline Jarque-Bera & 1.749937 & 0.693738 & 6.257464 & 1.568384 \\
\hline Probability & 0.416875 & 0.706898 & 0.043773 & 0.456488 \\
\hline Observations & 27 & 27 & 27 & 27 \\
\hline
\end{tabular}

Source: Author's Computation

Table 4.1 shows the descriptive statistics for the series. The results showed that the proportion of the rural population with access to improved water supply between 1990 and 2016 averaged $41.49 \%$. This is suggestive that more than half of the rural populations do not have access to improved water supply. It was equally observed that precipitations and temperature averaged 94.28 and 27.22 while the per capita carbon dioxide emissions averaged 0.541 metric tonnes per capita. The standard deviation shows that both the observations for improved access to rural water supply and the measures of climate change introduced in this paper clustered around their respective mean values. This is very promising and suggests that the series do not vary significantly overtime. The Jarque-Bera statistics and its corresponding probability values show that the variables except temperature are normally distributed at 5 percent level.

\subsection{Unit Root Test}

The KPSS was applied in this paper to test the null hypothesis unit root. The results are reported in Table 4.2

Table 4.2: KPSS unit root test results

\begin{tabular}{|l|l|l|l|l|l|}
\hline Variable & Levels test & First Difference test & \\
\hline & $\begin{array}{l}\text { LM } \\
\text { stat. }\end{array}$ & $\begin{array}{l}\text { Critical value } \\
(\mathbf{5 \%})\end{array}$ & $\begin{array}{l}\text { LM } \\
\text { stat. }\end{array}$ & $\begin{array}{l}\text { Critical value } \\
\mathbf{( 5 \% )}\end{array}$ & $\begin{array}{l}\text { Order } \\
\text { integration }\end{array}$ \\
\hline RUWA & 0.125 & 0.146 & 0.132 & 0.146 & I $(0)$ \\
\hline PRE & 0.155 & 0.146 & 0.046 & 0.146 & I $(1)$ \\
\hline TEM & 0.1045 & 0.146 & 0.359 & 0.146 & I $(0)$ \\
\hline PCO & 0.125 & 0.146 & 0.088 & 0.146 & I $(0)$ \\
\hline
\end{tabular}

Source: Author's Computation

The KPSS unit root test results in Table 4.2 shows that all the variables except precipitations are stationary at levels. This result suggests that the variables are mixed integrated with combinations 
of I (0) and I(1). The non-stationarity of precipitations could be attributed to the common characteristics of time series which often depict a unit root process. Consequently, the Hansen (1992) approach to cointegration was applied.

\subsection{Cointegration Test}

The cointegration test procedure proposed by Hansen (1992) was used to the null hypothesis of cointegration against the alternative of no cointegration. The result is summarized in Table 4.3.

Table 4.3: Hansen Cointegration test result

\begin{tabular}{|c|l|l|l|l|}
\hline \multicolumn{3}{|l|}{ Series: RUWA PRE TEM PCO } & & \\
\hline Null hypothesis: Series are cointegrated & \\
\hline & Stochastic & Deterministic & Excluded & \\
\hline Lc statistic & Trends (m) & Trends (k) & Trends (p2) & Prob.* \\
\hline 0.538620 & 3 & 0 & 0 & 0.1916 \\
\hline
\end{tabular}

Source: Author's Computation

The cointegration test result is depicted in Figure 4.3. From the result, it was observed that the test statistic value (0.539) depicted in column one of Table 4.3 with probability value $(0.1916)$ indicates that the variables are cointegrated. Thus, the null hypothesis that the series are cointegrated cannot be rejected at 5 percent level. This finding indicates that the parameters are stable.

\subsection{Estimation of the Cointegration Regression Model}

The FMOLS was applied in estimating the dynamic regression model. The results are summarized in Table 4.4.

Table 4.4: Cointegrating regression model

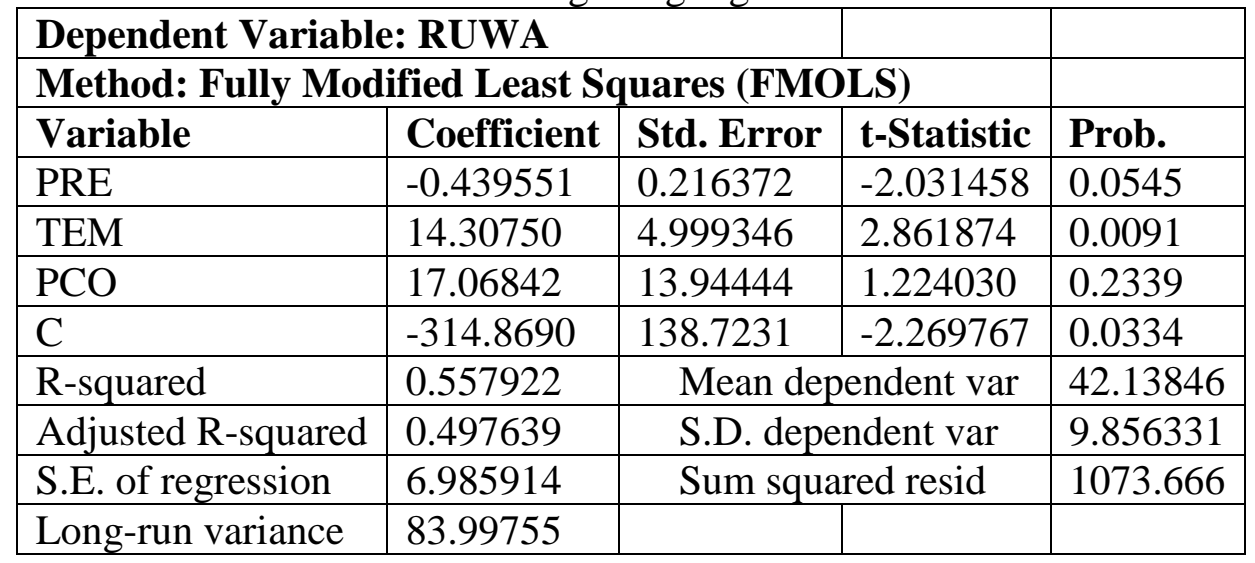

Source: Author's Computation

Table 4.4 shows the cointegrating regression result. It was found from the result that precipitation and temperature are significant in influencing changes in access to improved water supply in rural area. Whilst precipitations negatively influenced access to rural water supply, changes in temperature enhanced rural water supply. The negative effects of precipitations on rural water 
supply could be attributed to the flooding usually associated with incidences of climate change are envisaged in the AGW theory which tends to contaminate the water sources. On the other hand, per capita carbon dioxide emissions do not significantly affect access to improved water supply in rural areas. The coefficient of determination (0.557) reveals that the measures of climate change included in the model are responsible for 56 percent variations in access to improved water supply in rural communities.

\subsubsection{Post-estimation Test}

The post estimation tests results for the estimated cointegrating regression model are showed in Table 4.5-4.6 and Figure 4.1

Table 4.5: Wald test for joint significant of the regressors

\begin{tabular}{|c|c|c|c|}
\hline \multicolumn{2}{|c|}{ Wald Test: } & & \multirow[b]{3}{*}{ Probability } \\
\hline \multicolumn{3}{|c|}{ Equation: Untitled } & \\
\hline Test Statistic & Value & Df & \\
\hline F-statistic & 8.153983 & $(3,22)$ & 0.0008 \\
\hline Chi-square & 24.46195 & 3 & 0.0000 \\
\hline \multicolumn{4}{|c|}{ Null Hypothesis: $\mathrm{C}(1)=\mathrm{C}(2)=\mathrm{C}(3)=0$} \\
\hline \multicolumn{3}{|c|}{ Null Hypothesis Summary: } & \\
\hline \multicolumn{2}{|c|}{ Normalized Restriction $(=0)$} & Value & Std. Err. \\
\hline \multicolumn{2}{|c|}{$\mathrm{C}(1)$} & -0.439551 & 0.216372 \\
\hline \multicolumn{2}{|l|}{$\mathrm{C}(2)$} & 14.30750 & 4.999346 \\
\hline \multicolumn{2}{|l|}{$\mathrm{C}(3)$} & 17.06842 & 13.94444 \\
\hline
\end{tabular}

Source: Author's Computation

Table 4.6: Autocorrelation test

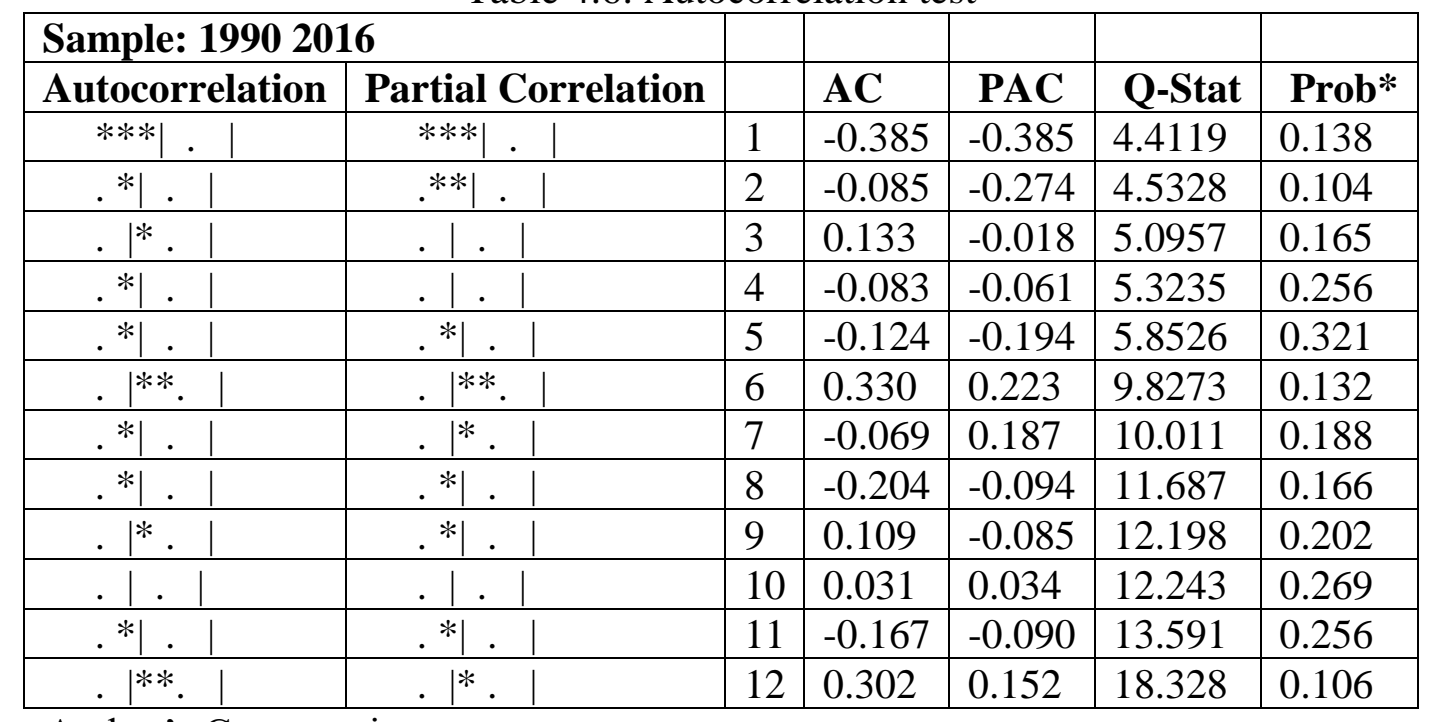

Source: Author's Computation 


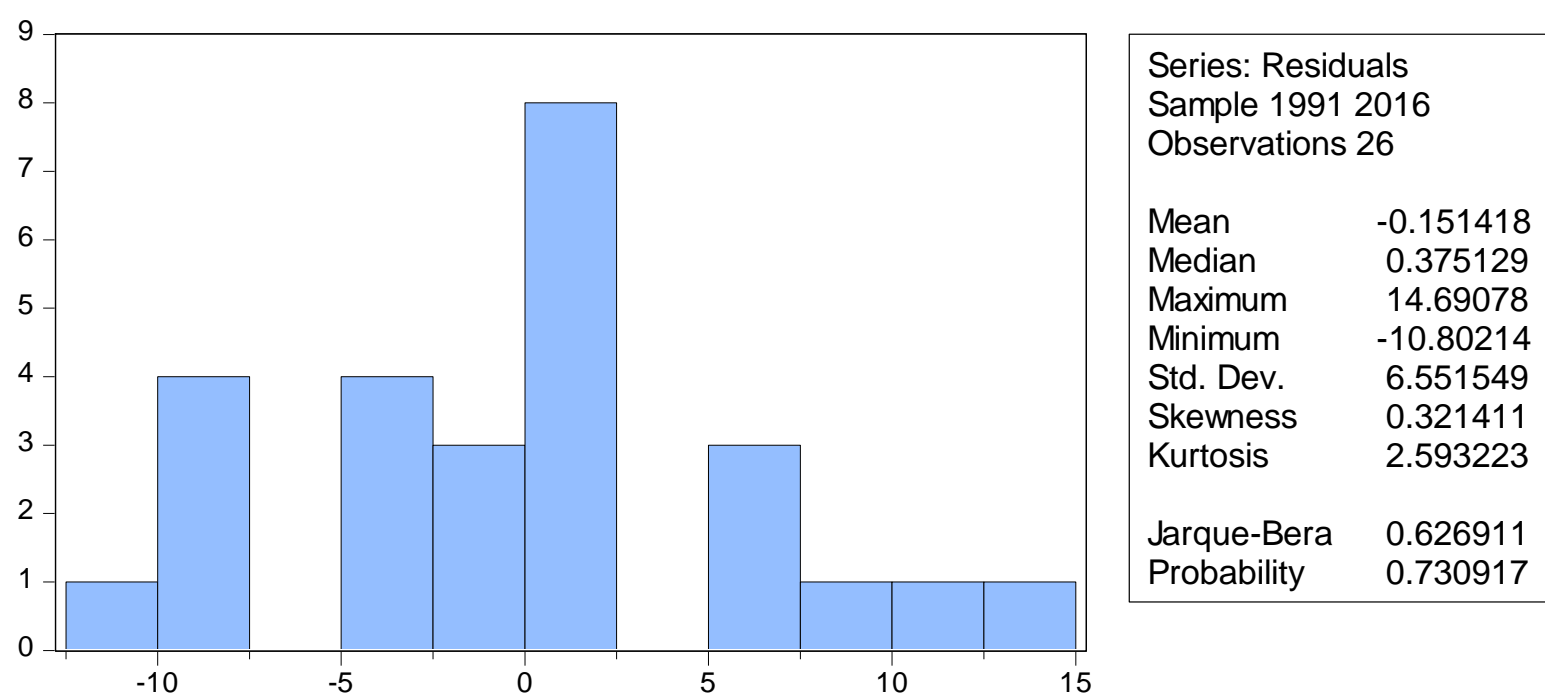

Figure 4.1: Residuals plot for normality test

Source: Author's Computation

The Wald test result in Table 4.5 reveals that the coefficients of the regressors are jointly significant at 5 percent level. This implies that the underlying measures of climate change in the model can jointly be relied upon in predicting changes in rural water supply. More so, the correlogram test for autocorrelation depicted in Table 4.6 indicates that the model is free from autocorrelation. This is because the probability values of the Q-statistics for the 12 lags exceeded 0.05. It was also observed from Figure 4.1 that residuals are normally distributed. The results of the post-estimation tests are very welcoming as they satisfy the econometric and statistical criteria.

\section{Conclusion and Recommendations}

In this paper efforts were made to provide deeper insights into the consequences of climate change on rural development. Access to improved water supply in the rural area was used to measure the extent of rural development while precipitations, temperature and per capital carbon dioxide emissions were employed as indicators of climate change. The results showed that precipitations exert significant negative impacts on access to rural water supply while changes in temperature are positively related to improved access to rural water supply. Given these findings, it is concluded that climate change plays key role in the development process of rural communities through its impacts on improved water supply. Hence, it is recommended for policy makers to adopt proactive and innovative approaches by synergizing with the relevant stakeholders to significantly address the problem of climate change and improve opportunities for rural development.

\section{References}

[1] Ayers, J.M and Huq, S., (2009). Supporting Adaptation to Climate Change: What Role for Official Development Assistance, Developmkent Policy Review, (6): 675-692

[2] Biggs, R., Simons, H., Bakkenes, M., Scholes, R.J., Eickhout, B., van Vuuren, D. (2008). Scenarios of biodiversity loss in southern Africa in the 21st century, Global Environmental Change,18(2),296-309. 
[3] Boyd, E., Grist, N., Juhola, S., \& Nelson V. (2009). Exploring Development Futures in a Changing Climate: Frontiers for Development Policy and Practice, Development Policy Review, 27 (6): 659674.

[4] Bunce M., Rosendo S. \& Brown K (2010). Perceptions of climate change, multiple stressors and livelihoods on marginal African coasts, Environment, Development and Sustainability,12(2),407440.

[5] Dube, T., \& Phiri, K. (2013). Rural livelihoods under stress: The impact of climate change on livelihoods in South Western Zimbabwe. American International Journal of Contemporary Research,3(5),11-25.

[6] Hansen, B. E. (1992). Efficient estimation and testing of cointegrating vectors in the presence of deterministic trends. Journal of Econometrics, 53(1-3), 87-121.

[7] Holmgren K. \& Oberg H., (2006). Climate Change in Southern and Eastern Africa during the past millennium and its implications for societal development; Environment, Development and Sustainability, 8: 185-195.

[8] Huq, N., Hugé, J., Boon, E., \& Gain, A. K. (2015). Climate change impacts in agricultural communities in rural areas of coastal Bangladesh: a tale of many stories. Sustainability, 7(7), 84378460 .

[9] Mano, R. \& Nhemachena C. (2007). Assessment of the Economic Impacts of Climate Change on Agriculture in Zimbabwe: A Ricardian Approach, World Bank Policy Research Working Paper, Available from http://econ.worldbank.org.

[10] Nhemachena, C., Hassan, R., \& Kurukulasuriya, P. (2010). Measuring the economic impact of climate change on African agricultural production systems. Climate Change Economics, 1(01), 3355.

[11] Ofoegbu, C., Chirwa, P., Francis, J., \& Babalola, F. (2017). Assessing vulnerability of rural communities to climate change: A review of implications for forest-based livelihoods in South Africa. International Journal of Climate Change Strategies and Management, 9(03), 374-386.

[12] Phillips, P. C. B., and Hansen, B. E. (1990). Statistical inference in instrumental variables regression with I(1) processes. Review of Economics Studies 57,99-125.

[13] WHO (2012). Progress on drinking water and sanitation, 2012 update. Geneva, Switzerland: World Health Organization.

[14] WHO, (2009). "Progress on Drinking Water andSanitation. A Millennium Development Goal MDG Assessment on progress for Children: A Report Card," 7th March, 2009. www.childinfo.org/water.html.

*Corresponding author.

E-mail address: dennisewubare@ yahoo.com 